\title{
Ventilation with Negative Airway Pressure Induces a Cytokine Response in Isolated Mouse Lung
}

\author{
Kuo-Chen Cheng, MD, Haibo Zhang, MD, PhD, Chang-Yi Lin, MD, and Arthur S. Slutsky, MD \\ Departments of Anaesthesia and Critical Care Medicine, St. Michael's Hospital, University of Toronto, Canada
}

\begin{abstract}
We tested the hypothesis that, under relatively low tidal volume (VT) mechanical ventilation, continuing lung decruitment induced by negative end-expiratory pressure (NEEP) would increase the lung cytokine response, potentially contributing to lung injury. Mouse lungs were excised and randomly assigned to one of 3 different ventilatory strategies: 1) the zero end-expiratory pressure group served as a control, 2) the NEEP7 group received a NEEP of $-7.5 \mathrm{~cm} \mathrm{H}_{2} \mathrm{O}$, and 3) the NEEP15 group received a NEEP of $-15 \mathrm{~cm} \mathrm{H}_{2} \mathrm{O}$. In all 3 groups, a VT of $7 \mathrm{~mL} / \mathrm{kg}$ was used. After $2 \mathrm{~h}$ of ventilation, lung lavage fluid was collected for measurements of tumor necrosis factor- $\alpha$, monocyte chemoattractant protein-1, and lactate dehydrogenase. Increases in plateau pressure before and after
\end{abstract}

mechanical ventilation were significantly greater in the NEEP15 group compared with the zero end-expiratory pressure group or NEEP7 group. Lung compliance was decreased in the NEEP15 compared with the other two groups. Concentrations of tumor necrosis factor- $\alpha$, monocyte chemoattractant protein-1, and lactate dehydrogenase in lung lavage were larger in the NEEP15 group than in the other groups. Atelectatic lung during repeated collapse and reopening of lung units accentuates the lung cytokine response that may contribute to lung injury even during relatively low VT mechanical ventilation.

(Anesth Analg 2002;94:1577-82)
$\mathbf{M}$ echanical ventilation has been used as an indispensable life-supportive therapy for respiratory failure (1). However, mechanical ventilation itself can induce a pulmonary inflammatory response and lung damage in the presence or absence of preexisting lung diseases (2). This form of ventilator-induced lung injury (VILI) has been called "biotrauma" (3). Several studies have shown that one of the mechanisms that causes VILI is alveolar overdistension, related to high airway pressure (4-6), or large tidal volumes $\left(\mathrm{V}_{\mathrm{T}}\right)(7-11)$.

In an isolated rat lung model, Tremblay et al. (2) demonstrated that mechanical ventilation with large $\mathrm{V}_{\mathrm{T}}$ and zero positive end-expiratory pressure (PEEP) induced an inflammatory response reflected by the production of cytokines, and lung injury assessed by compliance. Other studies have shown that mechanical ventilation with large $V_{T}$ results in an increased production of tumor necrosis factor- $\alpha$ (TNF- $\alpha$ ) and

Supported in part by Canadian Institutes of Health Research (MOP-44093 to HZ and MA-8558 to AS).

KCC is currently affiliated with the Department of Intensive Care Medicine, Chi Mei Foundation Hospital, Tainan, Taiwan.

CYL is currently affiliated with the Division of Respiratory Medicine, Mackay Memorial Hospital, Taipei, Taiwan.

Accepted for publication February 21, 2002.

Address correspondence and reprint requests to Arthur S. Slutsky, MD, Queen Wing, Room 4-042, 30 Bond St., Toronto, Ontario, Canada M5B 1W8. Address e-mail to arthur.slutsky@utoronto.ca. interleukin-6 in the systemic circulation $(12,13)$ that may contribute to the development of a systemic inflammatory response syndrome and perhaps distal organ dysfunction (14). We wondered whether lung inflammation could occur when the normal lung is ventilated with normal $\mathrm{V}_{\mathrm{T}}$ during repeated collapse and reopening.

Using a mean $\mathrm{V}_{\mathrm{T}}$ of $12 \mathrm{~mL} / \mathrm{kg}$ with a negative end-expiratory pressure (NEEP) of $-3 \mathrm{~cm} \mathrm{H}_{2} \mathrm{O}$, Taskar et al. (15) examined pulmonary clearance of ${ }^{99 \mathrm{~m}} \mathrm{Tc}$-diethylenetriamine pentaacetic acid, an index of the integrity of the alveolar-capillary barrier in a rabbit model. These investigators reported an increase in the clearance of $99^{\mathrm{m}} \mathrm{Tc}$-diethylenetriamine pentaacetic acid by the ventilatory strategy associated with a reduced lung volume (15). The same investigators also showed that a $V_{T}$ of $12 \mathrm{~mL} / \mathrm{kg}$ and a NEEP of $-3 \mathrm{~cm}$ $\mathrm{H}_{2} \mathrm{O}$ caused leakage of plasma proteins into alveoli when surfactant was depleted, suggesting that surfactant dysfunction makes the lung more vulnerable to repetitive collapse and reopening (16). However, the $12 \mathrm{~mL} / \mathrm{kg} \mathrm{V}_{\mathrm{T}}$ used in those studies $(15,16)$ might not be within a protective zone (i.e., $6-7 \mathrm{~mL} / \mathrm{kg}$ ). Thus, it remains unclear whether there is a correlation between lung derecruitment and injury using a $V_{T}$ that prevents overdistension. Because VILI is associated with the activation of various inflammatory cells and 
mediators (2), we examined the hypothesis that repetitive collapse and reopening of the lung initiates a cytokine response during normal $\mathrm{V}_{\mathrm{T}}$ ventilation. We used an ex vivo mouse lung model applying NEEP to test this hypothesis.

\section{Methods}

\section{Lung Isolation}

The study was approved by the animal use committee of the University of Toronto. Male A/J mice, aged 6 to $8 \mathrm{wk}$ weighing 20 to $30 \mathrm{~g}$ were anesthetized with an intraperitoneal injection of ketamine $(150 \mathrm{mg} / \mathrm{kg})$ and xylazine $(10 \mathrm{mg} / \mathrm{kg})$. A tracheostomy was performed followed by insertion of a $20 \mathrm{G}$ angiocatheter (Becton Dickinson, Sandy, UT). The lungs were then excised via a midline sternotomy.

\section{Ventilatory Setting}

The excised lungs were placed in a $37^{\circ} \mathrm{C}$ humidified plethysmograph and airway pressure was measured (MPX series pressure transducer; Motorola, Phoenix, AZ) and recorded over the ventilation period. Before initiating ventilation, the lungs were inflated to total lung capacity, defined as a transpulmonary pressure of $25 \mathrm{~cm} \mathrm{H}_{2} \mathrm{O}$, and sustained for $10 \mathrm{~s}$. After deflation, a pressure-volume (PV) curve was measured with injection of air in $0.05-\mathrm{mL}$ increments until a peak inspiratory pressure (PIP) reached $25 \mathrm{~cm} \mathrm{H}_{2} \mathrm{O}$. The lungs were then ventilated with a small-animal, volume-cycled ventilator (Voltek Enterprises Inc., Ontario, Canada) at a $\mathrm{V}_{\mathrm{T}}$ of $7 \mathrm{~mL} / \mathrm{kg}$ and a respiratory rate of 50 breaths per minute for $3 \mathrm{~min}$, before baseline PIP and plateau pressure (Pplat) were measured.

NEEP was established by connecting the expiratory port of the ventilator to a specially constructed chamber. The chamber consisted of a transparent plastic cylinder $60 \mathrm{~cm}$ high and $14 \mathrm{~cm}$ in diameter, attached in a vertical position to a circular base. The cylinder was filled about half way with water, and a rigid plastic tube of 3-mm inside diameter entered the chamber through a hole in the center of its circular top cover. An aquarium pump, modified to provide a suction port, was connected to another port on the top of the cylinder. When the end of the tube was placed below the water level, the negative pressure caused air from the outside to bubble through the water. The vertical position of the rigid plastic tube was adjustable to provide the required NEEP. The approximately $6 \mathrm{~L}$ of air in the cylinder above the water acted as a pressure buffer, so that the negative pressure during expiration remained nearly constant.

\section{Experimental Protocol}

After baseline measurements, the lungs were randomized into three ventilated groups using room air: Group 1 served as a control. The lungs were ventilated with a $\mathrm{V}_{\mathrm{T}}$ of $7 \mathrm{~mL} / \mathrm{kg}$ and zero end-expiratory pressure (ZEEP, $n=10$ ). Groups 2 and 3 served as test groups ventilated with a VT of $7 \mathrm{~mL} / \mathrm{kg}$ and 2 levels of NEEP. The lungs were ventilated either with a NEEP of $-7.5 \mathrm{~cm} \mathrm{H}_{2} \mathrm{O}$ (NEEP7, $n=10$ ) in Group 2, or with a NEEP of $-15 \mathrm{~cm} \mathrm{H}_{2} \mathrm{O}$ (NEEP15, $\left.n=10\right)$ in Group 3 .

Upon completion of $2 \mathrm{~h}$ of ex vivo ventilation, PIP, Plat, and PV curves were determined. The lungs were then lavaged 3 times by using $0.8 \mathrm{~mL}$ of cold normal saline. The lavage fluids were pooled and centrifuged. The supernatants were stored at $-70^{\circ} \mathrm{C}$ for measurement of cytokines and lactate dehydrogenate (LDH). The lungs were then filled with $4 \%$ formalin for pathologic examination.

\section{Cytokine Assays}

Cytokine analysis (TNF- $\alpha$, monocyte chemoattractant protein [MCP]-1) from the lung lavage fluid was performed in a blinded manner by using commercially available enzyme-linked immunosorbent assay kits (Biosource International Inc., Camarillo, CA).

\section{LDH Assays}

Cell injury was assessed by the measurement of LDH release in the lung lavage. A colorimetric assay of the Cytotoxicity Detection Kit (Boehringer Mannheim $\mathrm{GmbH}$, Germany) was used as described previously (17).

\section{Lung Histology}

The lungs were fixed by immersion in $10 \%$ buffered neutral formalin and were processed using standard histologic techniques. A pathologist read the morphologic slides in a blinded manner.

Data analysis was performed by using two-way analysis of variance followed by the Tukey-Kramer test. Significance was set at $P<0.05$. Results were reported as mean \pm SEM.

\section{Results}

Body Weight

The body weight of the mice was similar in the 3 groups of animals $(23.3 \pm 1.9 \mathrm{~g}$ in the ZEEP group, $23.7 \pm 0.7 \mathrm{~g}$ in the NEEP7 group, and $24.0 \pm 2.2 \mathrm{~g}$ in the NEEP15 group, $P=$ not significant [NS]).

\section{Lung Compliance (PIP, Pplat, and PV Curve)}

The basal PIP and Pplat were identical in the three groups. After $2 \mathrm{~h}$ of ventilation, the PIP increased 
Figure 1. The differences of plateau pressure ( $\Delta$ Pplat) $2 \mathrm{~h}$ before and after mechanical ventilation with a tidal volume of $7 \mathrm{~mL} / \mathrm{kg}$ in combination with zero endexpiratory pressure (ZEEP), $-7.5 \mathrm{~cm}$ $\mathrm{H}_{2} \mathrm{O}$ of negative end-expiratory pressure (NEEP7), or $-15 \mathrm{~cm} \mathrm{H}_{2} \mathrm{O}$ of negative endexpiratory pressure (NEEP15). ${ }^{*} P<0.05$ versus ZEEP.
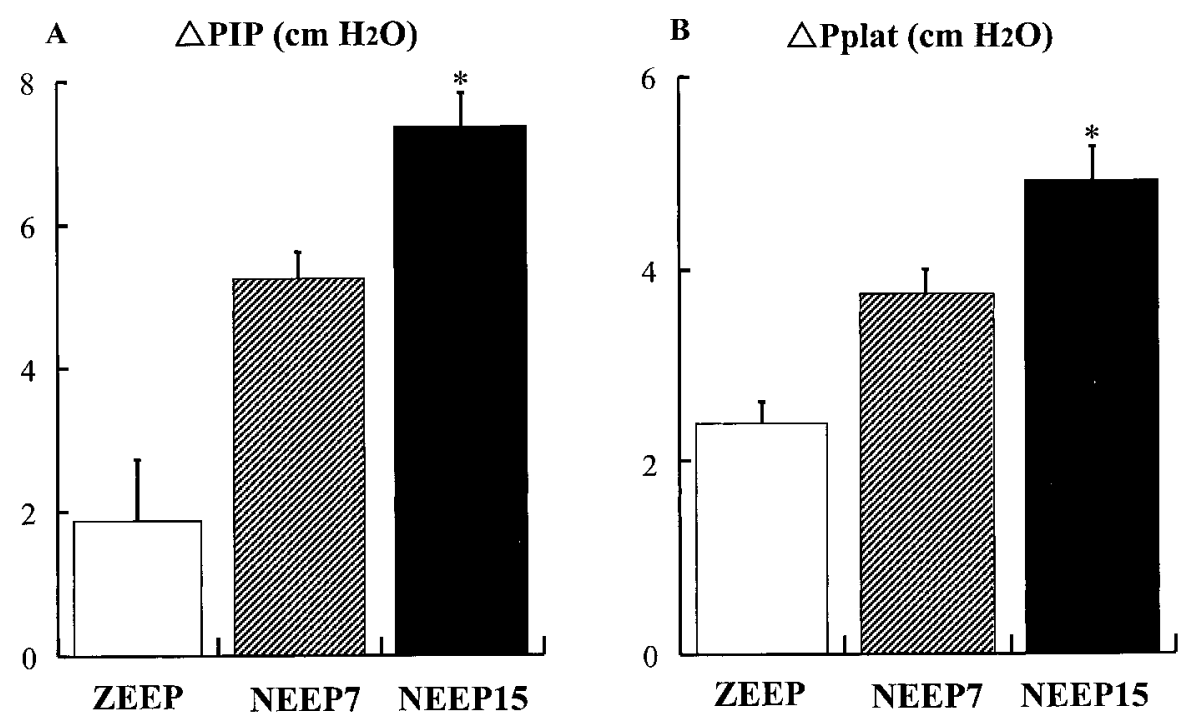

slightly from $25.0 \pm 1.0$ under baseline conditions to $26.9 \pm 0.7 \mathrm{~cm} \mathrm{H}_{2} \mathrm{O}$ in the ZEEP group $(P=\mathrm{NS})$; from $24.3 \pm 0.3$ in baseline to $31.0 \pm 1.0 \mathrm{~cm} \mathrm{H}_{2} \mathrm{O}$ in the NEEP7 group $(P=\mathrm{NS})$; and increased significantly from $25.0 \pm 0.2$ to $32.0 \pm 0.6 \mathrm{~cm} \mathrm{H}_{2} \mathrm{O}$ in the NEEP15 group $(P<0.05)$.

Pplat changed from $16.8 \pm 0.5$ to $19.1 \pm 0.5 \mathrm{~cm} \mathrm{H}_{2} \mathrm{O}$ in the ZEEP group $(P=\mathrm{NS})$, and from $17.7 \pm 0.2$ to $21.5 \pm 0.5 \mathrm{~cm} \mathrm{H}_{2} \mathrm{O}$ in the NEEP7 group $(P=\mathrm{NS})$, and from $17.3 \pm 0.4$ to $22.3 \pm 0.5 \mathrm{~cm} \mathrm{H}_{2} \mathrm{O}$ in the NEEP15 group $(P<0.05)$.

The changes of Pplat ( $\Delta$ Pplat) values before and after the ventilation were larger in the NEEP15 group than in the ZEEP group (Fig. 1).

The PV curves showed a greater downward shift to the right in the NEEP15 group than in the ZEEP group (Fig. 2). The lung volume at PIP $25 \mathrm{~cm} \mathrm{H}_{2} \mathrm{O}$ was significantly decreased in the NEEP15 group compared with the ZEEP group (Fig. 2). There was no significant shift of PV curves in the NEEP7 group (data not shown).

\section{Cytokines}

After $2 \mathrm{~h}$ of ventilation, the concentration of TNF- $\alpha$ and MCP-1 in the lung lavage fluid was significantly increased in the NEEP15 group compared with the ZEEP or NEEP7 group (both $P<0.05$ ) (Fig. 3).

\section{$L D H$}

The levels of LDH in lung lavage fluids were identical in the ZEEP and the NEEP7 groups but significantly increased in the NEEP15 group $(P<0.05)$ (Fig. 4).

\section{Lung Histology}

There was no significant difference in histologic examination in the three groups with respect to epithelial integrity (data not shown).

\section{Discussion}

We examined the effect of continuing lung decruitment using NEEP on lung cytokine responses to mechanical ventilation using a relatively small $\mathrm{V}_{\mathrm{T}}$. The $\mathrm{V}_{\mathrm{T}}$ of $7 \mathrm{~mL} / \mathrm{kg}$ we used has been suggested to be noninjurious by several studies in animals and in humans $(2,13,18)$. We observed a significantly larger $\Delta$ Pplat, a decreased lung compliance, an increased production of cytokines, and release of LDH in the NEEP15 group, suggesting an inflammatory response and cell injury. Our data thus indicate that the use of NEEP during normal $\mathrm{V}_{\mathrm{T}}$ ventilation increases the release of cytokines. This study also suggests that NEEP is a useful model for studying the effect of continuing decruitment during repetitive collapse and reopening of the lung. Although the ex vivo system has several advantages, such as allowing us to study the direct effects on the lung without the potential complications of cytokine influence from the circulation, this model also has limitations. The lack of a circulation with consequent ischemia may have contributed to the injury observed, but all three groups sustained equal periods of ischemia so that this factor was unlikely to be critical in this model.

Taskar et al. $(15,16)$ used a rabbit model and demonstrated that a NEEP as small as $-3 \mathrm{~cm} \mathrm{H}_{2} \mathrm{O}$ decreased lung compliance and oxygenation, and increased lung permeability (15), which was impaired even more if the lungs were depleted of surfactant 
ZEEP

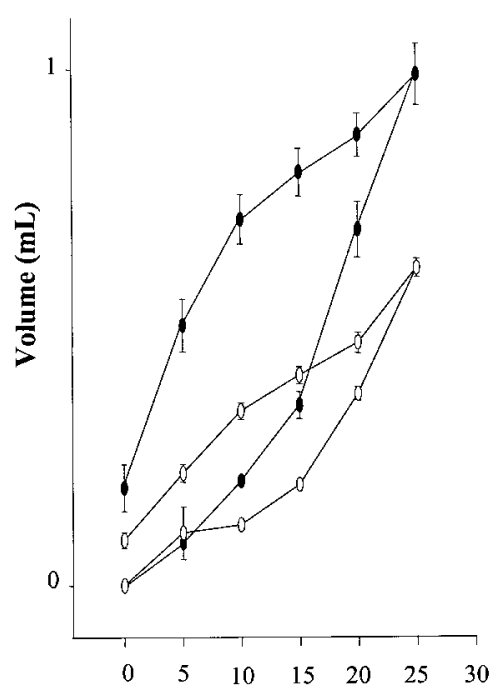

Pressure (cmH2O)

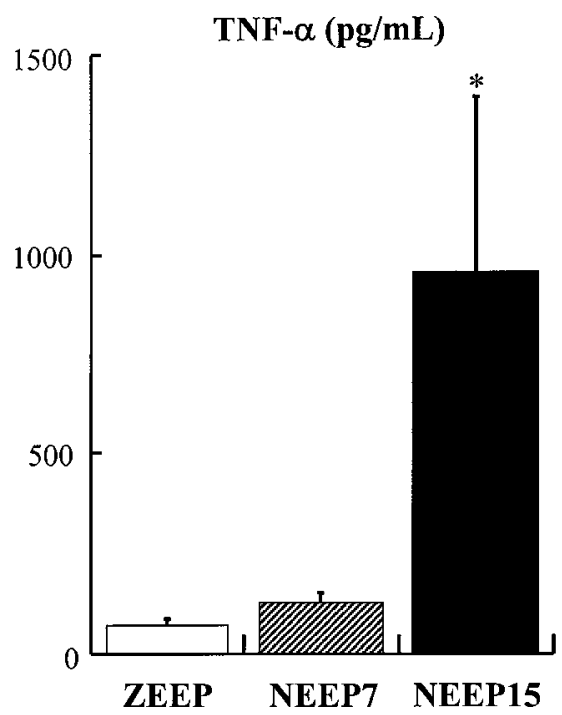

NEEP15

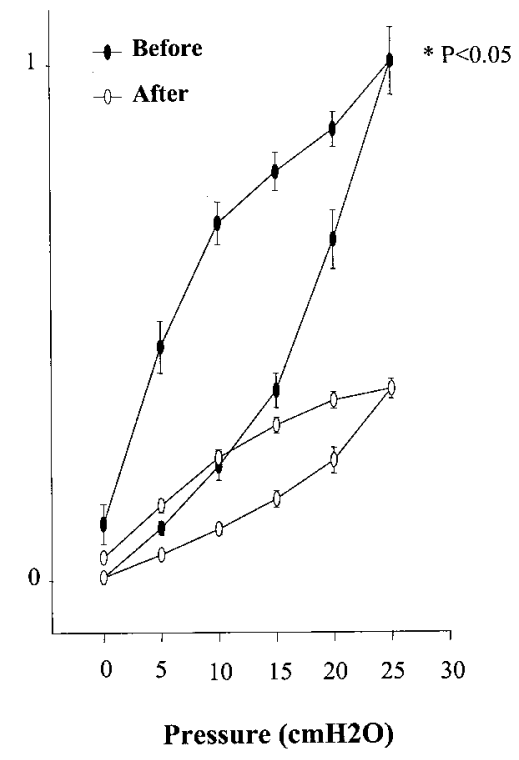

$\operatorname{MCP}-1(p g / m L)$

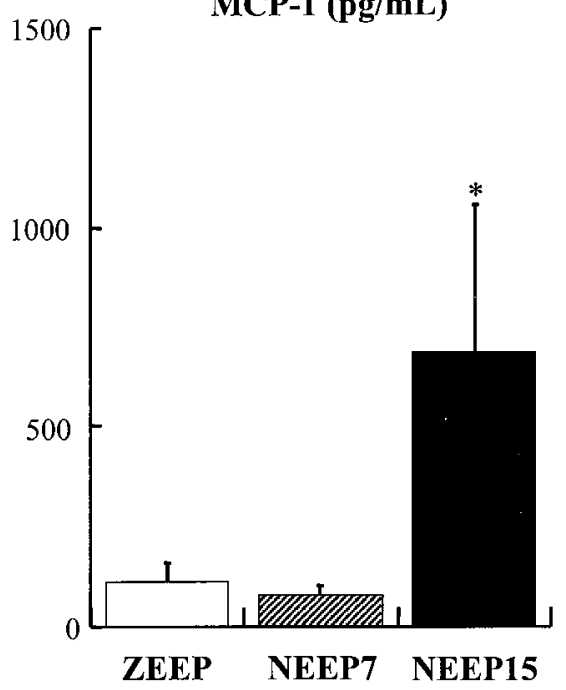

Figure 2. Mean values of pressure-volume curves before (upper curves) and $2 \mathrm{~h}$ after mechanical ventilation with a tidal volume of $7 \mathrm{~mL} / \mathrm{kg}$ and zero end-expiratory pressure (ZEEP) or $-15 \mathrm{~cm} \mathrm{H}_{2} \mathrm{O}$ of endexpiratory pressure (NEEP15). The curve showed a greater down-right shift in the NEEP15 group.

\begin{abstract}
Figure 3. Concentrations of tumor necrosis factor (TNF)- $\alpha$ and monocyte chemoattractant protein (MCP)-1 in lung lavage fluids of the 3 groups that were ventilated for $2 \mathrm{~h}$ with a tidal volume of $7 \mathrm{~mL} / \mathrm{kg}$ in combination with zero end-expiratory pressure (ZEEP), $-7.5 \mathrm{~cm} \mathrm{H}_{2} \mathrm{O}$ of negative end-expiratory pressure (NEEP7), or -15 $\mathrm{cm} \mathrm{H}_{2} \mathrm{O}$ of negative end-expiratory pressure (NEEP15). ${ }^{*} P<0.05$ versus ZEEP.
\end{abstract}

(16). However, our data showed that a NEEP of $-7 \mathrm{~cm}$ $\mathrm{H}_{2} \mathrm{O}$ did not induce any significant alterations with respect to cytokine responses and lung injury indices. Several factors may explain the apparent discrepancies in these observations. First, Taskar et al. $(15,16)$ used a $V_{\mathrm{T}}$ of $12 \mathrm{~mL} / \mathrm{kg}$, which may be relatively injurious compared with the $\mathrm{V}_{\mathrm{T}}$ of $7 \mathrm{~mL} / \mathrm{kg}$ that we used. Second, they compared lung injury indices between NEEP and PEEP $\left(2 \mathrm{~cm} \mathrm{H}_{2} \mathrm{O}\right)(15,16)$. The latter may be protective, so that the same injury induced by a NEEP of $-3 \mathrm{H}_{2} \mathrm{O}$ might not have been apparent if it had been compared with a ZEEP group as in the present study. Third, they used an in vivo model, which may have been associated with hemodynamic compromise during mechanical ventilation that could have contributed to the lung damage $(15,16)$. We focused on an ex vivo lung model to avoid any hemodynamic influences. Finally, there may be species differences that account for these findings.

This is the first report of a significant cytokine response to NEEP ventilation. We chose to measure TNF- $\alpha$ and MCP-1 in the present study because the cytokines are largely involved in lung injury. TNF- $\alpha$ may mediate many of the pathologic changes seen in acute respiratory distress syndrome (ARDS), including initiation of the cytokine cascade and an increase in lung permeability (19). MCP-1, a c-c chemokine family member, can be derived from monocytes and alveolar macrophages. The blockade of MCP-1 attenuates the development of lung injury (20). Because 


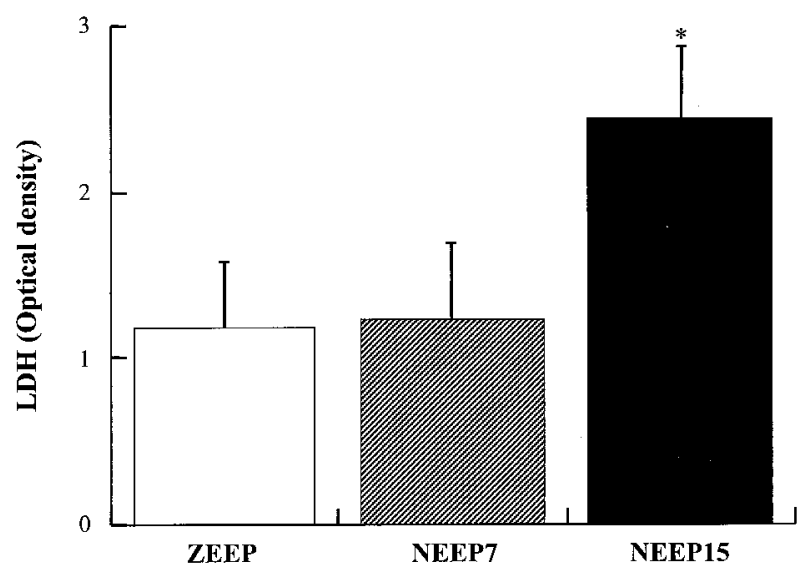

Figure 4. Values of optical density of lactate dehydrogenate (LDH) in BAL fluids of the 3 groups that were ventilated for $2 \mathrm{~h}$ with a tidal volume of $7 \mathrm{~mL} / \mathrm{kg}$ in combination with zero end-expiratory pressure (ZEEP), $-7.5 \mathrm{~cm} \mathrm{H}_{2} \mathrm{O}$ of end-expiratory pressure (NEEP7), or $-15 \mathrm{~cm} \mathrm{H}_{2} \mathrm{O}$ of end-expiratory pressure (NEEP15). ${ }^{*} P<0.05$ versus ZEEP.

alveolar macrophages are often involved in lung inflammation, we also measured MCP-1 production. We do not have evidence in this model of which cell type is producing the cytokines, but in a previous study, we found that the epithelial cells serve as a major source of TNF- $\alpha$ and interleukin- $6 .{ }^{1}$ The cytokine release was not necessarily related to lung structural alterations because no significant lung histologic damage was seen in this model, which may be attributable to the limited study period. However, both lung epithelial cells and inflammatory cells could be the major sources of the increased production of cytokines induced by mechanical stress as previously described in ex vivo studies $(21,22)$.

The release of $\mathrm{LDH}$, a product of glucose-pyruvate metabolism reflecting cell injury $(23,24)$, significantly increased only in the NEEP15 group. The sources of LDH could be from lung parenchyma and/or erythrocytes. Because no erythrocytes were found in the bronchoalveolar lavage fluid, we believe that the increased level of LDH was largely produced by lung tissue. Lung histologic examination did not demonstrate significant alterations by NEEP. Because LDH is a stable cytoplasmic enzyme present in all cells, and is rapidly released into the cell culture supernatant upon damage of the plasma membrane, our data suggest that LDH is a sensitive index of NEEP-initiated inflammation and injury at cellular levels during continuing lung decruitment before the development of a significantly altered lung histology. In support of the sensitivity of the LDH measurement with respect to cellular injury, we have previously observed a similar

\footnotetext{
${ }^{1}$ Tremblay L, Miatto D, Hamid Q, Slutsky AS. Changes in cytokine expression secondary to injurious mechanical ventilation strategies in an ex vivo lung model [abstract]. Intensive Care Med 1997;23:S3.
}

phenomenon when lung tissue was challenged by lipopolysaccharide (17).

The mechanisms by which NEEP induced lung cytokine response and cellular injury may be attributable to lung instability at end-expiration, resulting in lung injury even under ventilation with low $\mathrm{V}_{\mathrm{T}}$. This suggests that low $\mathrm{V}_{\mathrm{T}}$ may be protective only when the alveoli are kept relatively open at end-expiration. This concept is supported by recent studies in which Pelosi et al. (25) and Richard et al. (26) demonstrated that decruitment can occur during low $\mathrm{V}_{\mathrm{T}}$ ventilation, and repeated collapse and reopening of alveoli may have a predominant role in causing VILI even with noninjurious ventilation. This may have some relevance to the recently reported ARDSNet trial (18), which found a $22 \%$ decrease in mortality in the ARDS patients treated with $6 \mathrm{~mL} / \mathrm{kg}$ (predicted body weight). A recent study has suggested that one mechanism for decreased injury and mortality may be related to the generation of auto-PEEP in patients who received a high respiratory rate to maintain relatively normal values of $\mathrm{PaCO}_{2}$ (27). Thus, it may have been the compensation of low $V_{T}$ with somewhat increased PEEP that was protective. We do not exclude the possibility that an even lower $\mathrm{V}_{\mathrm{T}}$ ventilator setting might otherwise have avoided further VILI.

In conclusion, continuing lung decruitment during repeated collapse and reopening of lung units induced by NEEP accentuates the lung cytokine response and cell injury, even with ventilation using a relative normal value of $\mathrm{V}_{\mathrm{T}}$. This phenomenon may have clinical relevance in atelectasis-prone alveoli during mechanical ventilation in patients.

We thank George A. Volgyesi, P. Eng., for his technical assistance.

\section{References}

1. Tobin MJ. Principles and practice of mechanical ventilation. In: Colice GL, ed. Histological perspective on the development of mechanical ventilation. New York: McGraw-Hill, 1994:1-35.

2. Tremblay L, Valenza F, Ribeiro SP, et al. Injurious ventilatory strategies increase cytokines and c-fos m-RNA expression in an isolated rat lung model. J Clin Invest 1997;99:944-52.

3. Tremblay LN, Slutsky AS. Ventilator-induced injury: from barotrauma to biotrauma. Proc Assoc Am Physicians 1998;110: $482-8$.

4. Webb H, Tierney D. Experimental pulmonary edema due to intermittent positive pressure ventilation with high inflation pressures: protection by positive end-expiratory pressure. Am Rev Respir Dis 1974;110:556-65.

5. Dreyfuss D, Basser G, Soler P, Saumon G. Intermittent positivepressure hyperventilation with high inflation pressures produces pulmonary microvascular injury in rats. Am Rev Respir Dis $1985 ; 132: 880-4$.

6. Kolobow T, Moretti MP, Fumagalli R, et al. Severe impairment of lung function induced by high peak airway pressure during mechanical ventilation: an experimental study. Am Rev Respir Dis 1987;135:312-5. 
7. Dreyfuss D, Saumon G. Role of tidal volume, FRC, and endinspiratory volume in the development of pulmonary edema following mechanical ventilation. Am Rev Respir Dis 1993;148: 1194-203.

8. Dreyfuss D, Soler P, Basset G, Saumon G. High inflation pressure pulmonary edema: respective effects of high airway pressure, high tidal volume, and positive end-expiratory pressure. Am Rev Respir Dis 1988;137:1159-64.

9. Corbridge TC, Wood LDH, Crawford GP, et al. Adverse effect of large tidal volume and low PEEP in canine acid aspiration. Am Rev Respir Dis 1990;142:311-5.

10. Mead J, Takishima T, Leith D. Stress distribution in lungs: a model of pulmonary elasticity. J Appl Physiol 1970;28:596-608.

11. Hotchkiss JR Jr, Blanch L, Murias G, et al. Effects of decreased respiratory frequency on ventilator-induced lung injury. Am J Respir Crit Care Med 2000;161:463-8.

12. von Bethmann AN, Brasch F, Nusing R, et al. Hyperventilation induces release of cytokines from perfused mouse lung. Am J Respir Crit Care Med 1998;157:263-72.

13. Chiumello D, Pristine G, Slutsky AS. Mechanical ventilation affects local and systemic cytokines in an animal model of acute respiratory distress syndrome. Am J Respir Crit Care Med 1999; 160:109-16.

14. Dos Santos CC, Slutsky AS. Invited review: mechanisms of ventilator-induced lung injury-a perspective. J Appl Physiol 2000;89:1645-55.

15. Taskar V, John J, Evander E, et al. Healthy lungs tolerate repetitive collapse and reopening during short periods of mechanical ventilation. Acta Anaesthesiol Scand 1995;39:370-6.

16. Taskar V, John J, Evander E, et al. Surfactant dysfunction makes lungs vulnerable to repetitive collapse and reexpansion. Am J Respir Crit Care Med 1997;155:313-20.

17. Zhang H, Kim YK, Govindarajan A, et al. Effect of Adrenoreceptors on endotoxin-induced cytokines and lipid peroxidation in lung explants. Am J Respir Crit Care Med 1999;160:1703-10.
18. Ventilation with lower tidal volumes as compared with traditional tidal volumes for acute lung injury and the acute respiratory distress syndrome. The Acute Respiratory Distress Syndrome Network. N Engl J Med 2000;342:1301-08.

19. Freeman BD, Natanson A. Anti-inflammatory therapies in sepsis and septic shock. Expert Opin Investig Drugs 2000;9: 1651-63.

20. Jones ML, Mulligan MS, Flory CM, et al. Potential role of monocyte chemoattractant protein-1/JE in monocyte/macrophagedependent IgA immune complex alveolitis in the rat. J Immunol 1992;149:2147-54.

21. Vlahakis NE, Schroeder MA, Limper AH, Hubmayr RD. Stretch induces cytokine release by alveolar epithelial cells in vitro. Am J Physiol 1999;277:L167-73.

22. Pugin J, Dunn I, Jolliet P, et al. Activation of human macrophages by mechanical ventilation in vitro. Am J Physiol 1998; 275:L1040-50.

23. Behnia R, Molteni A, Waters CM, et al. Early markers of ventilator-induced lung injury in rats. Ann Clin Lab Sci 1996; 26:437-50.

24. Drent M, Cobben NA, Henderson RF, et al. Usefulness of lactate dehydrogenase and its isoenzymes as indicators of lung damage or inflammation. Eur Respir J 1996;9:1736-42.

25. Pelosi P, Goldner M, McKibben A, et al. Recruitment and derecruitment during acute respiratory failure: an experimental study. Am J Respir Crit Care Med 2001;164:122-30.

26. Richard JC, Maggiore SM, Jonson B, et al. Influence of tidal volume on alveolar recruitment: respective role of PEEP and a recruitment maneuver. Am J Respir Crit Care Med 2001;163: 1609-13.

27. Lee CM, Neff MJ, Steinberg KP, et al. Effect of low tidal volume ventilation on intrinsic PEEP in patients with acute lung injury [abstract]. Am J Respir Crit Care Med 2001;163:C91. 